\title{
The Effect of Using Plastic Strips and Sheets on the Properties of Slurry Infiltrated Fiber Concrete
}

\author{
Adraa M. Najeeb \\ Department of Civil Engineering \\ University of Baghdad \\ Baghdad, Iraq \\ a.najib1101@coeng.uobaghdad.edu.iq
}

\author{
Nada Mahdi Fawzi \\ Department of Civil Engineering \\ University of Baghdad \\ Baghdad, Iraq \\ nada.aljalawi@coeng.uobaghdad.edu.iq
}

\begin{abstract}
Slurry Infiltrated Fiber Concrete (SIFCON) is a highstrong material that is regarded as a unique type of high fiber content concrete. This paper aims to study the influence of the use of plastic strips and plastic sheets in the SIFCON slurry. Three sets (normal SIFCON as control, SIFCON with plastic strips, and SIFCON with plastic sheet), in a 1:1.08 cement-sand ratio by weight has been used with water to cement ratio $(\mathrm{w} / \mathrm{c})$ by weight equal to 0.3 , and superplasticizer equal to $1 \%$ by weight. In addition, $6 \%$ by volume crimped steel fibers with an aspect ratio of 60 were applied and $1.34 \%$ by volume plastic was used, in strips of $5 \times 1 \mathrm{~cm}$ for both prism and cube samples and in sheets of $25 \times 5 \mathrm{~cm}$ and $7 \times 7 \mathrm{~cm}$ for prism and cube samples respectively. The compressive and flexural strength tests studies were conducted on typical cubes of $10 \times 10 \times 10 \mathrm{~cm}$ and prisms of $40 \times 7 \times 7 \mathrm{~cm}$ respectively to find out the way the plastic affects the SIFCON properties. The results indicate that the models with plastic sheets placed in SIFCON slurry give the highest compressive and flexural strength whereas the models with plastic strips gave the lowest. The difference percentages in compressive and flexural strength were $-27.3,8,-3.8$ and $66.6 \%$ for all sets respectively when compared to the control set (using no plastic).
\end{abstract}

Keywords-SIFCON; plastic strips; plastic sheet; crimped fibers; aspect ratio

\section{INTRODUCTION}

There is a need to develop new forms of concrete that utilize fieldwork at reduced cost and in less time, therefore theoretical studies have been conducted utilizing building materials, additives, and sustainable materials of variopus types to create and discover types of concrete other than the conventional concrete, one of which is the Slurry Infiltrated Fiber Concrete (SIFCON). SIFCON is developed by increasing the percentage of steel fibers in the cement slurry. It has exceptionally high strength as compared to steel fibers reinforced concrete. SIFCON is an extra strong material that incorporates fibers in a high percentage volume [1]. SIFCON's matrix has no coarse particles but a high concentration of cementitious component. It may, however, incorporate fine (or coarse) sand as well as additives such as fly ash, micro silica, and latex emulsions. The ratios of cement and sand used to make SIFCON are typically $1: 1,1: 1.5$, or $1: 2$. The water cement ratio ranges from 0.3 to 0.4 . The percentage of superplasticizers in cement ranges from 2 to $5 \%$ by weight. The proportion of fibers by volume can vary from 4 to $20 \%$, while the present practical range is between 4 and $12 \%$ [2]. SIFCON is being frequently used, particularly in seismic modification design and in constructions subjected to impact forces. It also exhibits novel behavioral phenomena such as the fiber lock [3]. SIFCON is used within applications where large ductility and energy absorbing are required, such as seismic-resistant reinforced concrete members and structures subjected to unusual or exploding forces. Pavement toppings, pre-stressed beams repairs, and structural reinforced concrete element restoration are some of its other successful uses. In addition, it is used in military structures against blasts, industrial sites, runways, and bridge foundations [3, 4].

An investigation about the effectiveness of combining steel and polypropylene fibers in various combinations in the SIFCON had been studied using fibers to cover $1 / 1,1 / 3$, and $2 / 3$ of the molds in [5]. The mechanical and physical characteristics of SIFCON were investigated in this study. The usage of fibers in different combinations resulted in raising the fiber volume. The greatest flexural strength rates were obtained using specimens entirely filled with fibers, which were 44.02 $\mathrm{MPa}$ and $41.23 \mathrm{MPa}$ with steel fiber at lengths of $6 \mathrm{~cm}$ and $3.5 \mathrm{~cm}$ respectively, and with a composite of $6 \mathrm{~cm}$ steel and $5 \mathrm{~cm}$ polypropylene fiber. The usage of polypropylene fibers in conjunction with steel fibers enhanced fracture toughness and flexural strength. As a result, it had been discovered that polypropylene fibers offer great benefits over the use of SIFCON in terms of cost and unit weight due to their reduced cost and density.

The effect of adding steel fibers on the mechanical properties of concrete had been examined in [6] using fraction volumes of $0.5,0.75$, and 1 of concrete and an aspect ratio of 100. The study was conducted on ordinary concrete specimens (cubes and prisms) and on concrete reinforced with steel fibers that had been water cured. All the mixtures had the same volumetric percentage of coarse and fine aggregates, and the same amount of water, resulting in a constant $\mathrm{w} / \mathrm{c}$ ratio of 0.54 . The largest increase percentage in compressive strength for specimens of concrete reinforced with steel fibers cured in water for 90 days was $8,11.1$, and $17.1 \%$. The flexural strength of prisms cured in water increased with curing time. The 
maximum improvements at 90 days of curing for plain concrete and concrete reinforced with fiber for all sets were 30.4, 36.8, and $44.3 \%$ respectively.

Regarding the curing temperature of high performance concrete, the influence of curing temperatures of 30,40 , and $50^{\circ} \mathrm{C}$ on the compressive strength growth of high performance concrete was studied in [7]. The results were compared to concrete cured under standard circumstances at the usual curing temperature of $21^{\circ} \mathrm{C}$. The study findings revealed that at early ages, the rate of strength growth is larger at high than at reduced curing temperatures, with the greatest rising percentage in compressive strength at $50^{\circ} \mathrm{C}$. Yet, at older ages, the strength produced at elevated curing temperatures was lower than that produced at normal temperatures, and the greatest percentage of loss was $5.7 \%$ percent at the curing temperature of $50^{\circ} \mathrm{C}$ in 91 days curing age .

Self-Compacted Concrete (SCC) is considered to have advantages similar to SIFCON's, such as improved construction quality and faster construction activity. Various fibers were utilized in [8] as fiber reinforcement in SCC. They were proved to have a significant impact on the fresh and hardened characteristics of SCC. In most situations, the inclusion of fibers reduces the fresh characteristics of concrete (e.g. flow ability, passing ability, and segregation resistance), but increases the mechanical properties substantially. The kind and shape of fiber, aspect ratio, and volumetric fraction were found to be important parameters regarding the performance of SCC.

The aim of adding and promoting the usage of plastic waste in concrete was studied in [9]. The flexural strength and the workability of concrete were examined using different percentages of plastic fibers. M15 grade concrete beams were casted and cured for 7 and 28 days. The results showed that the use of plastic fibers reduced workability marginally while they increased flexural strength by $16.5 \%$ at $0.6 \%$ addition of plastic fibers in concrete [9].

\section{MATERIALS USED}

The investigation work has been carried out in the Civil Engineering Department's laboratory at the University of Baghdad. The used materials were:

- Ordinary Portland Cement type 42.5R complying to [10].

- Zone 4 sand complying to [11].

- Crimped steel fibers with a circular cross-section, with a length of $6 \mathrm{~cm}$, diameter of $0.1 \mathrm{~cm}$, and aspect ratio of 60 were utilized. Table I explains the characteristics of steel fibers, and Figure 1 depicts their form.

- Tap water complying with [12] was utilized.

- Sika ViscoCrete - 1316 Hi-Tech high range water reduction superplasticizer was utilized. The superplasticizer meets the Type D and G criteria of [13].

- The plastic strips used were $5 \mathrm{~cm}$ long and $1 \mathrm{~cm}$ wide and were cut from plastic water bottles (Figure 2).
- Plastic sheets, $25 \times 5 \mathrm{~cm}$ for prisms and $7 \times 7 \mathrm{~cm}$ for cubes having openings of $1 \times 1.5 \mathrm{~cm}$, were used (Figure 2 ).

TABLE I. STEEL FIBER PROPERTIES

\begin{tabular}{|c|c|c|c|c|c|c|}
\hline $\begin{array}{c}\text { Fiber } \\
\text { type }\end{array}$ & $\begin{array}{c}\text { Cross- } \\
\text { section }\end{array}$ & $\begin{array}{c}\text { Lengthl } \\
\mathbf{( m m})\end{array}$ & $\begin{array}{c}\text { Diameter } \\
\mathbf{( m m})\end{array}$ & $\begin{array}{c}\text { Aspect } \\
\text { ratio }\end{array}$ & $\begin{array}{c}\text { Density } \\
\mathbf{( k g / \mathbf { m } ^ { 3 } )}\end{array}$ & $\begin{array}{c}\text { Tensile } \\
\text { strength } \\
\mathbf{( M P a})\end{array}$ \\
\hline Crimped & Circular & 60 & 1 & 60 & 7870 & $>800$ \\
\hline
\end{tabular}

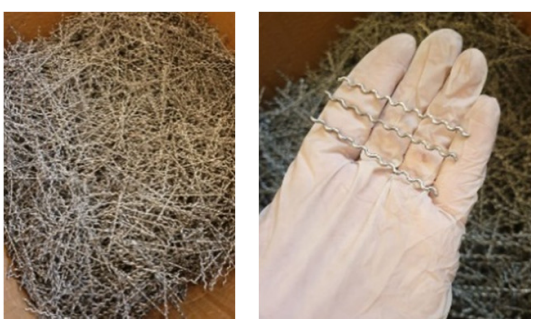

Fig. 1. Crimped steel fibers.

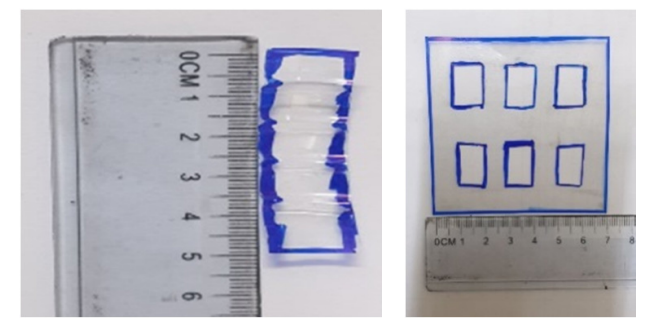

Fig. 2. Plastic strips and sheets.

III. MIXING DESIGN AND PROCEDURE

The cement-to-sand ratio was set at 1:1.08 by weight, the w/c ratio was set at 0.3 by weight, and the superplasticizer percentage was set at $1 \%$ by cement weight. Crimped steel fibers were utilized at a rate of $6 \%$ by volume. Cement and sand were mixed in their dry form. The superplasticizer was added to the water in a bowl and they were stirred until a homogeneous solution was produced. Then, the water with the superplasticizer were gradually added to the dried materials and blend until a homogeneous slurry mixture was obtained. Before casting, all the molds $(10 \times 10 \times 10 \mathrm{~cm}$ cubes and $40 \times 7 \times 7 \mathrm{~cm}$ prisms) were cleaned and lubricated. For the first SIFCON set (control set), a thin layer of the slurry was placed in the molds and then the entire fiber quantity was placed at once. Another layer of slurry was placed over the fibers and it was let to be penetrated by them. For the second set of SIFCON with plastic strips, a thin layer of the slurry was put into the molds first, followed by the fibers with plastic strips all at once, and then another layer of the slurry was poured over the fibers. For the last set, a layer of slurry was first placed in the molds, followed by a layer of fibers and slurry, then the plastic sheet was placed in the middle. Afterward, again one layer of fibers and one of slurry were placed and let to penetrated. To ensure that there are no honeycombs inside the specimens, the molds were lightly knocked on the outer face. The top surface of the specimens does not need to be level because the mixture is slurry and claims a level face on its own. Regarding demolding, all specimens were submerged in a basin with tap water at room temperature in accordance with [14], until testing time. 


\section{TEST PROCEDURES}

\section{A. Compressive Strength Test}

The compressive strength test was performed on the $10 \times 10 \times 10 \mathrm{~cm}$ cubes in accordance with [15]. This test was carried out using a compressive strength hydraulic machine with $2000 \mathrm{KN}$ capacity at fixed load (Figure 3 ). The outcomes are the average of cubes for each set at ages of 7 and 28 days.

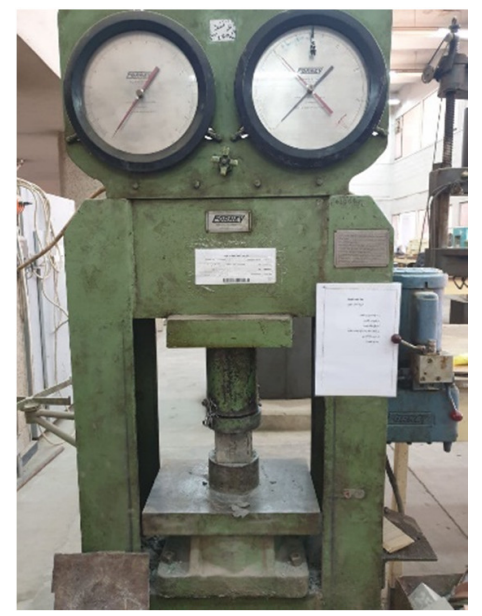

Fig. 3. Compressive strength measuring equipment.

\section{B. Flexural Strength Test}

The flexural strength test was carried out in accordance with [16] employing the $40 \times 7 \times 7 \mathrm{~cm}$ prisms. This test was performed with the use of a flexural strength test machine with capacity up to $400 \mathrm{KN}$ (Figure 4 ). The average of each batch at ages of 7 and 28 days was used as the final result.

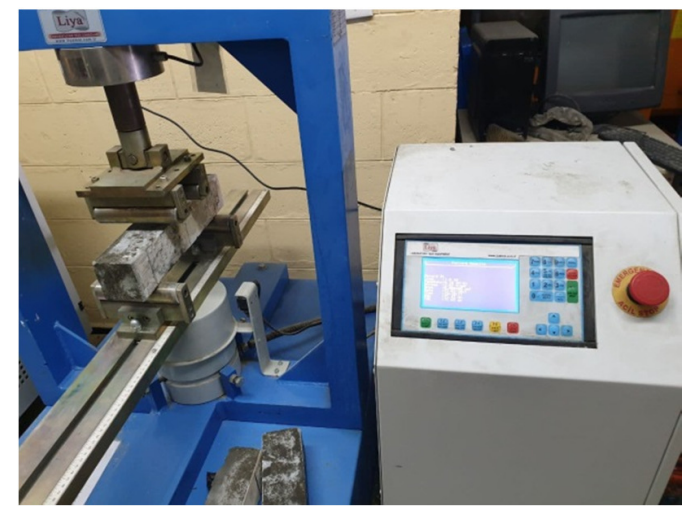

Fig. 4. Flexural strength measuring equipment.

\section{RESULTS AND DISCUSSION}

\section{A. Compressive Strength Test Results}

The cubes prepared for compressive strength test were inspected at the age of 7 and 28 days for all sets. The outcomes show that adding plastic sheet in the SIFCON mixture gives higher results than the mixture with the plastic strips and the control, while the results of plastic strip SIFCON are lower than the other two sets. The reason for the enhanced results when the plastic sheets are present is the contribution of the sheets in keeping the steel fibers distributed over the entire model without falling to the bottom due to their higher density. The reason for the presence of holes in the plastic sheets is that they allow the slurry to penetrate the entire form without accumulating on the top of the sheets. The reason for the reduction in the outcomes when the plastic strips are present is the relatively large cross section of the plastic strip, which leads to the heterogeneity of the specimens, which in turn leads to the reduction in the outcome. Table II and Figures 5-7 show the outcomes of the compressive strength tests. The outcomes of this study are higher than the ones in $[17,18]$.

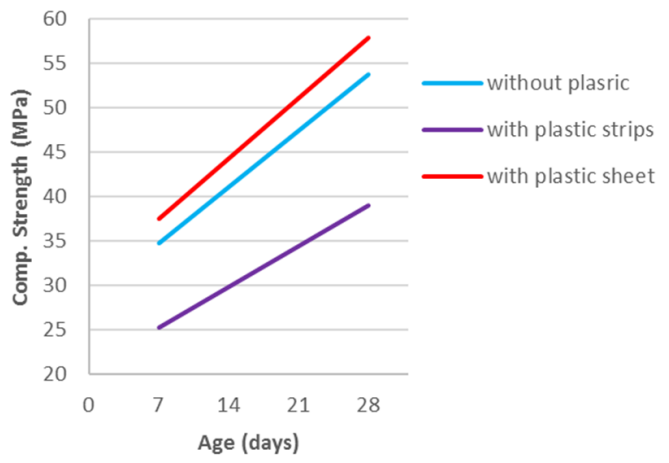

Fig. 5. Compressive strength change with age.

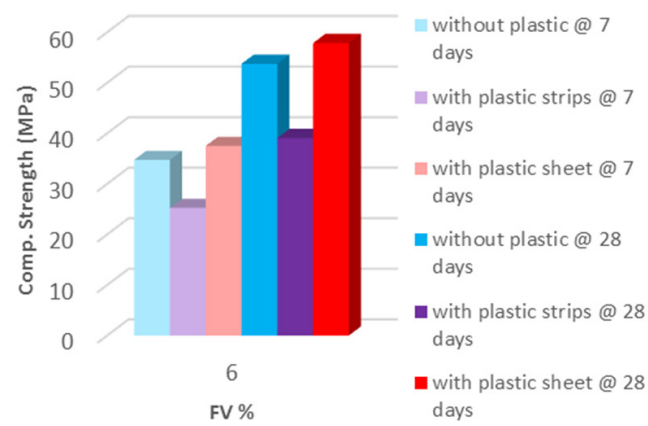

Fig. 6. Compressive strength change with age when using $6 \%$ steel fibers.

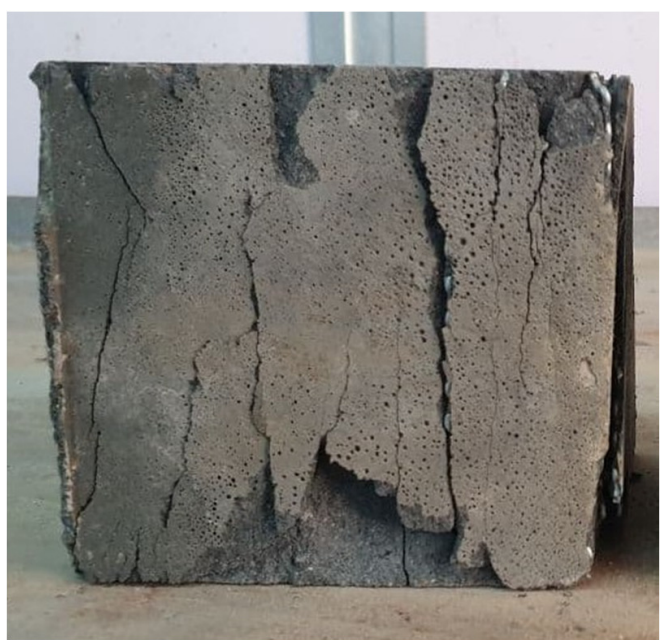

Fig. 7. Sample for tested for compressive strength after failure. 


\section{B. Flexural Strength Test Results}

The specimens showed no deformation during the flexural strength testing. The fibers have been removed from the hardened slurry, in contrast to the plastic that remained conjoined, indicating that the adhesion between the fibers and the hardened slurry has been overcome. Despite this, the adhesion between the hardened slurry and the fibers is excellent, agreeing with the findings in [5].

The prisms were tested for flexural strength at 7 and 28 days. The outcomes demonstrate that, the set using plastic sheets between the SIFCON slurry layers performed better than the set using plastic strips and the control mix, while the set using plastic strips produced the worst results. The enhanced results of the set containing plastic sheets were caused by the homogeneity of the respective samples which kept the fibers distributed over the entire sample. The negative outcomes of the set containing plastic strips must be attributed to the nonhomogeneity of the samples due to the relatively large cross section of the plastic strips. The outcomes of this paper are higher than the ones in $[9,19]$. Table II and Figures 8-10 show the outcomes of the flexural strength tests.

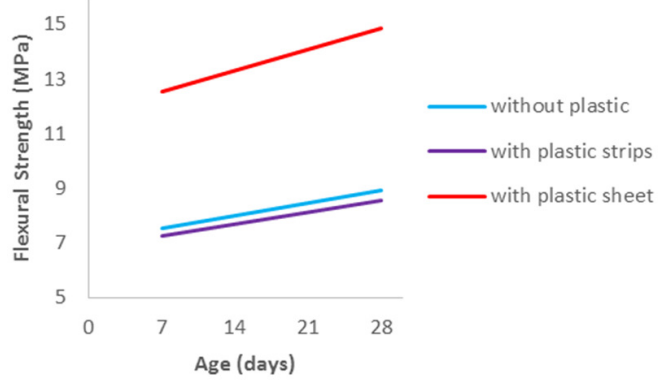

Fig. 8. Flexural strength change with age.

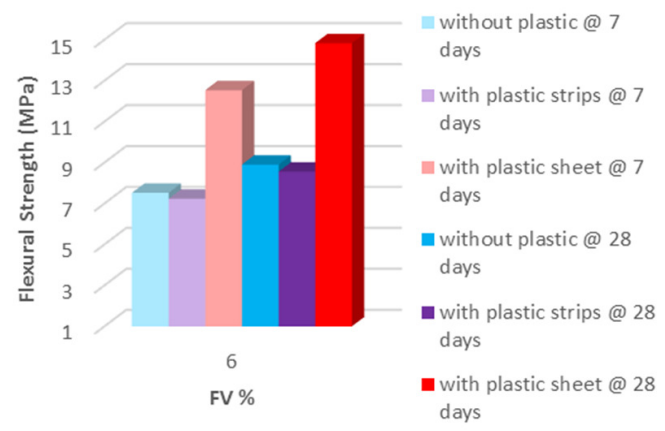

Fig. 9. Flexural strength change with age when using $6 \%$ steel fibers.

As a result summary, incorporating plastic sheets between the SIFCON's slurry layers gives an enhanced result regarding compressive and flexural strength since the specimens are having good distribution of fibers over the entire model. Incorporating plastic strips along with steel fibers inside the SIFCON slurry reduces the outcomes of compressive and flexural strength tests due to the cross section of the plastic strips used which leads to uneven steel fiber distribution in the samples.

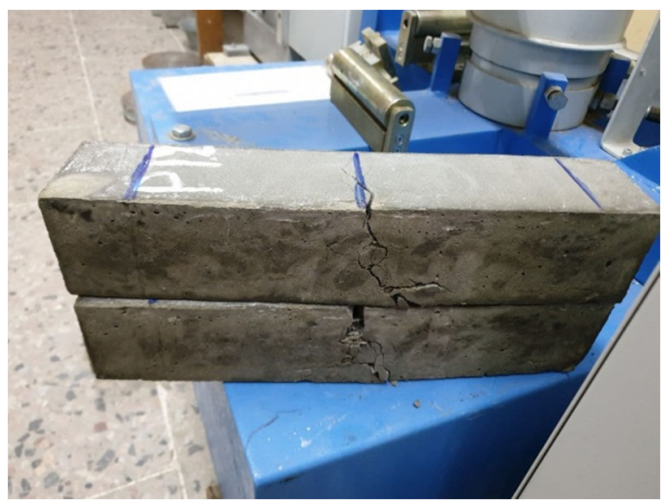

Fig. 10. A sample for flexural strength test after failure.

TABLE II. RESULTS OF COMPRESSIVE AND FLEXURAL STRENGTH TESTS

\begin{tabular}{|c|c|c|c|c|c|c|}
\hline Set & \multicolumn{2}{|c|}{ Control set } & \multicolumn{2}{|c|}{$\begin{array}{c}\text { SIFCON with } \\
\text { plastic strips } \\
\text { set }\end{array}$} & \multicolumn{2}{|c|}{$\begin{array}{l}\text { SIFCON with } \\
\text { plastic sheet set }\end{array}$} \\
\hline \multirow{3}{*}{$\begin{array}{l}\text { Compressive } \\
\text { strength (MPa) }\end{array}$} & \multicolumn{6}{|c|}{ Age (day) } \\
\hline & 7 & 28 & 7 & 28 & 7 & 28 \\
\hline & 34.72 & 53.74 & 25.23 & 39.04 & 37.50 & 57.84 \\
\hline \% Change & \multicolumn{2}{|c|}{0} & \multicolumn{2}{|c|}{-27.3} & \multicolumn{2}{|c|}{8} \\
\hline \multirow{3}{*}{$\begin{array}{c}\text { Flexural } \\
\text { strength (MPa) }\end{array}$} & \multicolumn{6}{|c|}{ Age (day) } \\
\hline & 7 & 28 & 7 & 28 & 7 & 28 \\
\hline & 7.52 & 8.89 & 7.23 & 8.55 & 12.53 & 14.83 \\
\hline \% Change & \multicolumn{2}{|c|}{0} & \multicolumn{2}{|c|}{-3.8} & \multicolumn{2}{|c|}{66.6} \\
\hline
\end{tabular}

\section{CONCLUSIONS}

In this study, used plastic was re-used as a sustainable material in SIFCON mixes. The outcomes of this investigation obtained from using $10 \times 10 \times 10 \mathrm{~cm}$ cubes and $40 \times 7 \times 7 \mathrm{~cm}$ prisms with $6 \%$ steel fibers and plastic strips or sheets. The samples were cured for 7 and 28 days and then their compressive and flexural strength was tested. As a conclusion of this investigation the following points should be noted:

- The results of compressive strength tests demonstrate that the use of plastic sheets within the SIFCON enhanced the results by about $8 \%$. The combination of plastic strips with steel fibers in SIFCON gives a reduction in the results of about $27.3 \%$.

- The flexural strength test outcomes clarify that the plastic sheets used within the SIFCON improve the result by about $66.6 \%$, while using plastic strips with steel fibers in SIFCON reduces the result by about $3.8 \%$.

\section{REFERENCES}

[1] K. Dagar, "Slurry Infiltrated Fibrous Concrete (SIFCON)," International Journal of Applied Engineering and Technology, vol. 2, no. 2, pp. 99$100,2012$.

[2] R. Giridhar and P. R. M. Rao, "Determination of Mechanical Properties of Slurry Infiltrated Concrete (SIFCON)," International Journal For Technological Research In Engineering, vol. 2, no. 7, pp. 1366-1368, Mar. 2015.

[3] S. A Salih, Q. J. Frayyeh, and M. A. Al-wahab Ali, "Flexural Behavior of Slurry Infiltrated Fiber Concrete (SIFCON) Containing Supplementary Cementitiouse Materials," Journal of Engineering and Sustainable Development, vol. 22, no. 2, pp. 35-48, 2018, https://doi.org/10.31272/jeasd.2018.2.32. 
[4] N. Soylu and A. F. Bingöl, "Research on effect of the quantity and aspect ratio of steel fibers on compressive and flexural strength of SIFCON," Challenge Journal of Structural Mechanics, vol. 5, no. 1, p. 29, Mar. 2019, https://doi.org/10.20528/cjsmec.2019.01.004.

[5] M. Ipek and M. Aksu, "The effect of different types of fiber on flexure strength and fracture toughness in SIFCON," Construction and Building Materials, vol. 214, pp. 207-218, Jul. 2019, https://doi.org/10.1016/ j.conbuildmat.2019.04.055

[6] S. Alaa and D. Aljalawi, "Effect of Petroleum Products on Steel Fiber Reinforced Concrete," Journal of Engineering, vol. 19, no. 1, pp. 16-43, Jan. 2013.

[7] N. M. Fawzi and A. S. T. Agha, "The Effect Of Curing Types On Compressive Strength Of High Performance Concrete," Journal of Engineering, vol. 18, no. 7, pp. 768-783, 2012.

[8] N. A. Memon, M. A. Memon, N. A. Lakho, F. A. Memon, M. A. Keerio, and A. N. Memon, "A Review on Self Compacting Concrete with Cementitious Materials and Fibers," Engineering, Technology \& Applied Science Research, vol. 8, no. 3, pp. 2969-2974, Jun. 2018, https://doi.org/10.48084/etasr.2006.

[9] M. T. Lakhiar, S. Sohu, I. A. Bhatti, N. Bhatti, S. A. Abbasi, and M. Tarique, "Flexural Performance of Concrete Reinforced by Plastic Fibers," Engineering, Technology \& Applied Science Research, vol. 8, no. 3, pp. 3041-3043, Jun. 2018, https://doi.org/10.48084/etasr.2084.

[10] Iraqi Standard No. 5: Portland Cement. Baghdad, Iraq: Central Organizationfor Standardization and Quality Control, 2019.

[11] Iraqi Specification No. 45: Iraqi Specification Limits for Aggregates Test from Natural Sources for Concrete and Building Constructions. Baghdad, Iraq: Central Agency for Standardization And Quality Control, 1984.

[12] Iraqi Specification, No .1703: Water Used for Concrete and Mortar. Baghdad, Iraq: Central Organization for Standardization and Quality Control, 2018.

[13] ASTM C494 / C494M-15, Standard Specification for Chemical Admixtures for Concrete. West Conshohocken, PA: ASTM International, 2015.

[14] "Standard Practice for Making and Curing Concrete Test Specimens in the Laboratory," ASTM International, West Conshohocken, PA, USA, ASTM C192/C192M-07.

[15] BS EN 12390-4:2019: Testing hardened concrete - Compressive strength. Specification for testing machines. London, UK: British Standards Institution, 2019.

[16] BS EN 12390-5:2019: Testing hardened concrete - Flexural strength of test specimens. London, UK: British Standards Institution, 2019.

[17] A. A. Thomas and J. Mathews, "Strength and Behaviour of Sifcon with Different Types of Fibers," International Journal of Civil Engineering and Technology, vol. 5, no. 12, pp. 25-30, Dec. 2014.

[18] S. A. Khan and G. Selvaraju, "Characteristic of Slurry Infiltrated Fibrous Concrete (SIFCON) Produced by Partially Replacing Cement by Mineral Admixtures and Steel Fibers by Waste Plastic Fibers," Journal of Advanced Research in Engineering Knowledge, vol. 7, no. 1, pp. 1$15,2019$.

[19] B. H. A. Bakar, A. T. Noaman, and H. M. Akil, "Cumulative Effect of Crumb Rubber and Steel Fiber on the Flexural Toughness of Concrete," Engineering, Technology \& Applied Science Research, vol. 7, no. 1, pp. 1345-1352, Feb. 2017, https://doi.org/10.48084/etasr.854. 